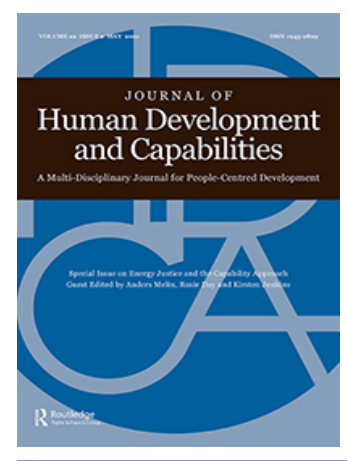

Journal of Human Development and Capabilities

A Multi-Disciplinary Journal for People-Centered Development

ISSN: (Print) (Online) Journal homepage: https://www.tandfonline.com/loi/cjhd20

\title{
Compensation for Energy Infrastructures: Can a Capability Approach be More Equitable?
}

Fausto Corvino, Giuseppe Pellegrini-Masini, Alberto Pirni \& Stefano Maran

To cite this article: Fausto Corvino, Giuseppe Pellegrini-Masini, Alberto Pirni \& Stefano Maran (2021) Compensation for Energy Infrastructures: Can a Capability Approach be More Equitable?, Journal of Human Development and Capabilities, 22:2, 197-217, DOI: 10.1080/19452829.2021.1887106

To link to this article: https://doi.org/10.1080/19452829.2021.1887106

曲 Published online: 04 Mar 2021.

Submit your article to this journal ๘

Џll Article views: 137

Q View related articles $₫$

View Crossmark data $\nearrow$ 


\title{
Compensation for Energy Infrastructures: Can a Capability Approach be More Equitable?
}

\author{
Fausto Corvino ${ }^{a}$, Giuseppe Pellegrini-Masini ${ }^{b}$, Alberto Pirni ${ }^{c}$ and \\ Stefano Maran ${ }^{\text {' }}$ \\ ${ }^{a}$ Department of Philosophy and Educational Sciences, University of Turin, Torino, Italy; ${ }^{b}$ Department \\ of Psychology, Norwegian University of Science and Technology, Trondheim, Norway; 'Sant'Anna \\ School of Advanced Studies, DIRPOLIS Institute (Law, Politics and Development), Pisa, Italy; ${ }^{\text {d Ricerca }}$ \\ sul Sistema energetico SpA, Sustainable Development and Energy Sources Department (SFE), Milano, \\ Italy
}

\begin{abstract}
In this article, we deal with the evaluation of the losses suffered by persons living in urban areas as a result of energy services. In the first part, we analyse how by adopting different informational foci we obtain contrasting interpersonal evaluations regarding the same loss. In the second part, we distinguish between a diachronic and a hypothetical/moralised threshold for harm in order to assess whether individuals are benefiting from or being harmed by a given energy service. Our argument is that the most accurate evaluation of an individual damage caused by an energy service can be obtained by using capabilities as informational focus, instead of realised wellbeing or means to wellbeing, and by interpreting the loss in relation to a hypothetical/moralised threshold that corresponds to a list of central capabilities. In the last part, we address monetary and non-monetary compensations for a loss that is evaluated in terms of capabilities. Accordingly, we expound how compensation policies can either restore the capabilities lost due to energy services or monetarily compensate the individual for the fact that a given capability (or set of capabilities) has been irremediably lost.
\end{abstract}

\section{KEYWORDS}

Adaptive preferences; capabilities; compensation; energy justice; harm

Energy justice has recently emerged as a distinctive branch of multidisciplinary research, within the more general field of socio-economic justice, and it has been open to contributions from ethicists, economists, scientists and political theorists, which are moved by the very empirical consideration that the way we produce, allocate, use energy and manage waste is yielding negative externalities which should either be corrected or compensated for. It is usually maintained that energy justice consists of three pillars: distribution, recognition and

CONTACT Fausto Corvino fausto.corvino@unito.it $\Theta$ Department of Philosophy and Educational Sciences, University of Turin, Palazzo Nuovo, Via Sant'Ottavio, 20, 10124 Turin (TO)

This article has been corrected with minor changes. These changes do not impact the academic content of the article.

(c) 2021 Human Development and Capability Association 
procedural justice (McCauley 2018, 14-17; Jenkins et al. 2016; PellegriniMasini 2020a).

In this article we shall focus on the role that moral and political philosophers can play in relation to two specific questions concerning the distributive dimension of energy justice: 1) what is the object of energy justice, or in other words what is the 'thing' that we should redistribute among the subjects of the scheme of distribution-e.g., realised wellbeing, resources or capabilities (the currency); 2) what is the baseline that we employ for measuring losses and gains - it can either be historical or moral (see Pogge 2008, 19-26; Meyer 2003; Boonin 2014, $56-65){ }^{1}$

Our aim in this work is to address these two questions by analysing their implications for the notion of the individual damage caused by an energy service (IDES), with a specific focus on the urban landscape. We use the expression 'energy service' in a broad sense, referring not only to the enduses of energy, but also to its production, transport and extraction. Accordingly, we take an IDES to occur whenever a new infrastructure dedicated to the production, transmission and consumption of energy has some negative impacts on a specific individual (or group of individuals) and, at the same time, it benefits another individual (or group of individuals). ${ }^{2}$ Normally, it can be observed that energy infrastructures represent a net cost for those individuals who live close to them and a net advantage for the community. The idea that energy infrastructures might cause damage to the population residing in their proximity is well rooted in literature (J. H. Sorensen, J. Sorensen, and Carnes 1984; Eyre 1997; Welsch 2016). These costs are considered negative externalities, which are defined as 'unpriced, unintended and uncompensated side effects of one agent's actions that directly affect the welfare of another agent' (Welsch 2016, 60). The need of addressing the problem of compensation for damages caused by the siting of energy infrastructures is considered a challenge for the development of future energy systems (Welsch 2016) and it has been argued that it should be a priority for an agenda of policy research guided by the principles of energy justice (Pellegrini-Masini 2020b).

These issues are becoming increasingly more important in view of the need to speed up the energy transition and the decarbonisation of the economic activities. This huge effort will drive the transformation of the whole energy system and the modernisation of most energy infrastructures, from the construction of large capacities of renewable power to the development of the electricity grid. Local communities, affected by the new infrastructures, will carry a great burden for the success of the energy transition, a clear example being the impairment of the landscape, in the interest of the general public. This makes very urgent the question how to compensate the negative effects suffered by citizens as a result of the development of energy infrastructures that are required for the energy transition. 
Compensation is the last step of a process of containment and minimisation of the negative impacts expected, through the application of the criteria of precaution, prevention and mitigation (mitigation hierarchy, see e.g., Enetjärn et al. 2015). Compensation aims to rebalance, with one or more actions, the residual negative impact due to the project, and its character should be homogeneous with that of the damaged compartment. For instance, the compensation of an environmental impact should consist of environmental measures and not only of economic or social ones, avoiding, as far as possible, monetisation. This provision is well established and can be traced back, for instance, to the original document of the Ramsar Convention (UNESCO 1971, art. 4.2), according to which 'where a Contracting Party in its urgent national interest, deletes or restricts the boundaries of a wetland included in the List, it should as far as possible compensate for any loss of wetland resources, and in particular it should create additional nature reserves for waterfowl and for the protection, either in the same area or elsewhere, of an adequate portion of the original habitat'. In practice, compensation measures are often the result of a private negotiation between the owner of the energy infrastructure and the municipality where the infrastructure is to be built (see, e.g., RGI 2018). This practice gives rise to several problems, from the asymmetry in knowledge and resources between the parties in the negotiation to the identification of the beneficiaries, and it makes urgent a reflection on implied justice aspects.

In this paper, we discuss the different, possible approaches to compensation, in the framework of energy justice, and we start outlining how the capability approach could be used for deciding on the siting of energy infrastructures. This is the first step towards the implementation of the approach in the current practices that could lead to a real improvement of the justice-related aspects of the energy transition and, considering the opposition that sometimes is experienced by new energy developments, it could ease the process and even contribute to make this transition possible.

Furthermore, by discussing the social benefits and costs of energy services in terms of capabilities, we intend to contribute to a broader definition of the concept of energy development. As we shall see, we will maintain that marginal increases in energy development do not result from the mere expansion of energy services, but from the enlargement of individual capabilities driven by these services (see also Day, Walker, and Simcock 2016). To this, we also add the further claim that variations in access to energy services, due to the acceleration or slowdown of energy developments, should not be read in a diachronic perspective that spans from the creation to the decommissioning of energy infrastructures, but rather should be measured against a morally predetermined baseline, which consists in a set of basic capabilities.

The article is structured as follows. In section $I$, we discuss the implications of different currencies of justice for the evaluation of IDES. In section II we wonder whether in assessing the right compensation for an IDES we should 
take as a benchmark a condition that the subject experienced in her personal history, or rather a moralised hypothesis that is not historical. Our argument is that only a subjunctive interpretation of IDES that is based on lost capabilities can yield a comprehensive account of this peculiar trade-off between costs and advantages. Accordingly, in section III we analyse different forms of monetary and non-monetary compensation that can restore the capabilities lost because of energy services.

\section{Energy, Damages and Capabilities}

When reasoning about justice it is of paramount importance to start from the distinction about the three different parameters (currencies) that can be adopted as measures of wellbeing and, accordingly, as informational bases of justice: realised achievements, means to achievement and freedoms to achieve (Sen 1992, 31-55; 1999, 54-110; See also Arneson 2000). If we look at realised achievements for evaluating and comparing different individual positions in social arrangements, it means that we are interested in how much happiness and satisfaction people obtain from the resources they have at their disposal, regardless of how much resources they control. A clear example of this approach can be found in the utilitarian doctrine. Consider, as an explicative case, two benefits, $A$ and $B$, that are different in magnitude $(A>B)$ and that accrue to two different persons, $\mathrm{X}$ and $\mathrm{Y}$, and yield the same marginal utility on their respective utility functions (muA-X $=$ muB-Y). From the utilitarian perspective, these two benefits have the same value, both for descriptive and for normative purposes, notwithstanding that one is bigger than the other (See also Mulgan 2007, 61-92).

Conversely, if we adopt means to achievement as our informational base, we ought to maintain that the distribution of benefits $A$ and $B$ has been unequal in regard to individuals $\mathrm{X}$ and $\mathrm{Y}$, because even though muA-X $=$ muB- $\mathrm{Y}$, what only matters in our evaluation is that $\mathrm{A}>\mathrm{B}$. This is the philosophical tendency that has characterised, from the 1970s, Rawlsian and post-Rawlsian normative political theory (see Vallentyne and Tungodden 2013). Lastly, if we replace means to achievements with freedoms to achieve, we should not simply linger on a quantitative comparison between $\mathrm{A}$ and $\mathrm{B}$, rather we should focus both on the potential of the recipients, $\mathrm{X}$ and $\mathrm{Y}$, to convert $\mathrm{A}$ and $\mathrm{B}$ into wellbeing and on the 'capability set of alternatives' they have in addition to A and B (Sen 1999, 75). Accordingly, a distribution in which X and Y exactly control the same set of resources cannot be considered as equal if these two individuals have the possibility to get two different levels of wellbeing from these equal resources (see Sen 1999, 70-72; Robeyns 2017, 21-58).

In Sen's terminology, we can say that life consists in a variety of functionings, which are all the 'various things a person may value doing or being' (Sen 1999, 75) -e.g., being nourished, receiving education, tasting single malt scotch 
whiskeys, and so on. Whenever an individual realises a valued functioning, she increases her wellbeing. Then we have capabilities, which are all 'the alternative combinations of functionings that are feasible for her to achieve' (Sen 1999, 75). Capabilities are the measure of the freedom to achieve wellbeing, which, according to Sen, is the correct parameter for evaluating the position of any individual in society - in contrast to realised wellbeing and means to wellbeing (See also Robeyns 2017, 38-44; Alkire 2008).

How is this discourse on wellbeing assessment relevant to energy justice? Firstly, it is relevant in so far as by adopting different informational bases for interpreting the meaning of 'worse off' we obtain conflicting results regarding the existence and the evaluation of damages and losses. Most environmental economists, for example, use realised wellbeing as their metric. They postulate that the value of a given environmental asset cannot be defined a priori, but instead reflects individual preferences which, presumably, maximise the individual utility and in doing so are also Pareto-efficient from a collective point of view (see Bromley and Paavola 2002). Thus, there could be cases in which the individuals acting within these models end up in the grips of adaptive preferences, that is to say of the psychological phenomenon by virtue of which low levels of experienced conditions move down the bar of expectations (Sen 1999, 62-63, 67-70; Nussbaum 2000, 111-166; Elster 1983; Bovens 1992;)-so falling back on a reductionist interpretation of harm.

If, on the contrary, we recur to a neutral estimate of lost and gained resources - or means to achievement-we would completely overlook that both social and individual factors have a heavy influence on the individual conversionpaths of commodities into wellbeing. This is what happens within those other models that either aim to identify the value of an environmental or social asset regardless of prices (i.e., in terms of individual preferences at the margin) but rather on the basis of what is supposed to be its intrinsic value (a typical example is a mountain landscape in an area where no one wants to live or go on vacation, or a suburban urban park that no one is using), or measure energy poverty in relation to the total amount of energy accessible to given households, without considering the fact that two different individuals who have access to the same amount of energy could get from it two different marginal increases in well-being, due to physical differences (e.g., age, illness, etc.), atmospheric differences (e.g., living in extremely cold or extremely hot places) or social differences (e.g., living in social contexts where work relationships or simple hospitality require compliance with a certain internal temperature threshold) (see also Day, Walker, and Simcock 2016; Wood and Roelich 2019).

Secondly, by shifting the focus from functionings to capabilities, the theory that we propose here allows to assess the contribution of energy services to energy developments in a context-sensitive way, i.e., not simply looking at the absolute value of energy infrastructures, but assessing, instead, the pathways 
through which specific individuals in specific communities convert services into well-being. And this obviously opens to the conclusion that, for example, two identical infrastructures can undergo different processes of conversion into wellbeing, in two different communities (due to either individual or social heterogeneities), thus giving rise to two different results in terms of variations in energy developments. Moreover, interpreting energy developments as enlargement of individual capability-sets means that it does not matter what things people do or stop doing after the provision of energy services, but what things people are free to do and to be, regardless of whether they decide to actually do or be these things (see also Hillerbrand 2018).

Thirdly, capabilities can help us to define a threshold of damage from energy infrastructures that is not historical but subjunctive. This allows to shift the assessment of the energy infrastructures, and its impact on energy developments, from a diachronic perspective to a broader moral valuation, which takes into account not only the impact of the infrastructure in terms of variations in individual capability sets, but also what the infrastructure could have done to enable the realisation of capabilities that were poorly developed even before the facility was commissioned.

As a matter of exemplification, consider a case in which we have to choose, as a local public authority, where to install an energy facility, and we have two options: either in proximity to a decentred but wealthy residential area, where the new structure would substantially deprive the inhabitants of the green spaces they usually hang out at, or rather in a poor suburb, where it would replace an abandoned social centre that was initially conceived for promoting reading culture. If we look at this issue from the perspective of realised achievements, we could have reasons enough for concluding that the facility would have a more negative impact, in terms of marginalities, on the utility functions of the people living in the wealthy neighbourhood - because we can imagine that it would deprive them of the green spots where they spend a significant amount of their leisure time. Whereas, the inhabitants of the other area would suffer, in comparison, a smaller loss in utility, given that they were not using the area that the facility might take over.

Nonetheless, it is very likely that by limiting the informational focus to realised achievements we might fall prey, in cases like this one, to evaluative distortions due to adaptive preferences. The latter can either be read from the perspective of rational choice theory or in purely normative terms (See Barnes 2009). From the first perspective, an adaptive preference accounts to a nonautonomous change in preferences that is irrational and therefore unusable for the purpose of measuring individual well-being. Where non-autonomous means that it does not derive from a conscious process aimed at changing preferences, and the typical example is that of an individual who is unable to obtain a certain functioning and therefore convinces herself that this functioning is irrelevant for her wellbeing (Elster 1983; Bovens 1992; Bruckner 2009). From 
the second perspective, an adaptive preference can be interpreted as the renunciation of one or more capabilities in the face of restricted options, which counts as either unreliable for wellbeing assessment (Sen 1999, 62-63) or as normatively wrong whenever the capabilities the individual gives up are considered as objectively constitutive of a life that has value, regardless of the degree of awareness or unreasonableness of the individual (Nussbaum 2000, 111-166; 2001). Accordingly, a person who adapts to live in a context of oppression has made a lowering of one's expectations of wellbeing that it is wrong to take into consideration, while a person who initially yearns for an object, and then after discovering that this object costs a lot convinces herself that this object would not bring a great increase to her well-being, is not necessarily making a wrong adjustment, neither from an axiological nor from a normative point of view.

Let us assume, returning to our case, that people from the suburban area were not profiting from the opportunity of the cultural centre because they have never been given the chance of discovering the beauty of literature. Or in other words, because the activities that were promoted in the centre -e.g., reading groups, presentations, and so on-required a previous knowledge about literature and reading skills that the majority of people in that area do not have. Under these circumstances, we may be faced with a case of adaptive preferences in both versions.

On the one hand, the renunciation of the use of the centre would seem not to be a rational choice, but rather a consequence of the fact that the majority of the inhabitants of the neighbourhood have not been provided with the educational assistance and stimuli necessary to cultivate a passion for the humanities. On the other hand, one could propose a normative argument that it is unfair that some people are deprived of the capability to enjoy things like theatre and literature. After all, the capability to enjoy art and humanities is what Nussbaum would define as a 'combined' capability, in the sense that its fruition requires 'suitable external conditions' (Nussbaum 2000, 84-85) that only society can provide to the individual - in this case in terms of schooling, educational opportunities, and so on.

Therefore, from a purely utilitarian perspective, it might be correct to say that people in the residential area suffer a bigger loss than people in the suburbs, but this occurs because the latter have got used to living a life without cultural activities of the kind that were proposed in the social centre. Yet, the fact that they do not register it as a loss on their utility functions does not necessarily entail that depriving them of the social centre is more just than depriving some other people of some other things that have an impact on their respective utility functions. For in cases like the one we are discussing, looking only at realised achievements for the purpose of harm evaluation can become a self-absolutory strategy for reinforcing entrenched inequalities (See also Corvino 2019, 528-536). 
An alternative solution might consist in looking at means to achievements instead of realised achievements. If we do so, the loss of the social centre and the loss of the green area could be weighted on objective economic terms, on the basis of their value as assets, without taking into consideration heterogeneities among end-users. The advantage of this second evaluative approach over the previous one is that it does not penalise people from the suburban area for not having the capability to profit from the social centre. The disadvantage, on the other hand, consists in the fact that by taking resources as the sole informational base for IDES, we give up on any evaluation on the different impact of this form of harm among members of the social group. Moreover, we might also incur in situations in which the economic loss does not correspond to a loss in wellbeing and this is not due to adaptive preferences.

Regarding the first point, we can easily notice that if we focus only on resources, we should consider as equal the loss that the energy facility would impose either on a person who has the cultural knowledge that is required for enjoying the cultural activities of the social centre or on another person that is completely illiterate. Even though we have reasons to hold that both persons have suffered a loss - according to the arguments we have discussed before-it seems unreasonable to hold that they have suffered the same loss. Regarding the second point, let us imagine an overturning of our example, in which those that do not use the area that might be taken over by the facility are the people who live in the residential neighbourhood. And this is not due to them lacking any combined capability required to enjoy green spots, rather it occurs because they simply prefer to hang out in the city centre. The approach based on resources would assign the same value to the harm that the facility might inflict in the residential area both in the original example and in the overturned version. This indifference seems unreasonable from a moral point of view.

Only an evaluation based on lost capabilities would yield a comprehensive estimate of IDES that is immune from reductionist conclusions due to adaptive preferences, takes into consideration the use that people make of lost resources -apart from their economic value-and allows for differentiation due to heterogeneities in the individual process of conversion of resources into wellbeing. ${ }^{3}$ Thus, in our original example, we could make the general claim that with the installation of the facility, people from the suburb would lose the capability for participating with others in cultural activities, notwithstanding that this is a combined capability that requires some social preconditions to be exercised, because the fact that some people have not yet received the social contribution for the fruition of a combined capability does pose the problem of providing this contribution, instead of being a justification for denying the combined capability tout court. Conversely, people from the wealthy neighbourhood would lose the capability for hanging out in green spots nearby their houses, that is mostly an internal rather than a combined capability, because it 
becomes exercisable with the normal development of human functions, as walking for example - while the capability for playing does also have a combined component.

Therefore, by limiting the analysis to this general claim, we can evaluate the dimension of IDES in the two scenarios on the basis of two indicators: the centrality of lost capabilities and the number of people involved. Obviously, these indicators can provide quite accurate results regarding where to place a given IDES on an ordinal scale, while it is admittedly more difficult to assign cardinal values (Comim 2008; Alkire 2005; Alkire et al. 2015). Going back to our example, if we are only interested in assessing which of the two losses is more serious, hence which one should be avoided, we can firstly wonder whether the capability for hanging out in green spots near home is more or less important than the capability for participating in shared cultural activities. The response to this question is political. We would say that the second capability is more central than the first one, but our aim in this part of the paper is descriptive rather than normative, hence we shall leave the issue open. Obviously, every decision-maker that would want to adopt the evaluative criterion for losses that we are proposing here would need to blend it into her more general ethical and moral beliefs. And she would also have to take into consideration the second indicator, namely the number of people that are at risk of losing any of the two different capabilities.

At this point, it might be worth stressing that we are only tackling the issue how to measure an IDES, independently of any broader theory of socio-economic justice within which we might want to frame our evaluation of the loss. Therefore, it might be perfectly coherent to hold that the damage that people from the suburb would suffer from the energy facility is smaller than the damage to people from the wealthy area, but that, notwithstanding this fact, we prefer, for egalitarian convictions, to inflict a bigger damage to the better off rather than a small damage to the worse off. ${ }^{4}$

Conversely, if we are interested in a cardinal evaluation of IDES, rather than in a comparison, because we want to assess which correlative compensation is due, capabilities would surely have problems in providing precise numbers that correspond to monetary quantities, but they have the great advantage of being malleable with regards to the possible non-monetary ways of restoration. In other words, even though it might be difficult to assess what is the economic value of the capability for participating in shared cultural activities, it is much easier to come up with solutions for guaranteeing this capability that are alternative to the abandoned social centre. In the fourth section, we shall deal with the issue of non-monetary restoration of capabilities that are lost due to energy services. However, before getting into it, it is important to respond to the fourth question about energy justice to which political philosophers should find a plausible 
answer: should we interpret energy harm in a diachronic or in a subjunctive sense? Or maybe in both senses? The following section will be dedicated to this conundrum.

\section{Diachronic vs. Subjunctive Interpretation of Damages Caused by Energy Services}

We have argued that, from a person-affecting prospective ${ }^{5}$, we can maintain that a given energy service brings harm to a given agent - or group of agents - when it causes the agent to be worse off in comparison with a baseline that represents our benchmark for no-harm. In the previous section, we have analysed all the different senses in which the agent can be considered as worse off than she would have been at the no-harm baseline. And we have concluded that we have cogent reasons for adopting capabilities as our evaluative metric. Now we shall focus, instead, on how we get the no-harm baseline. Does it correspond to the condition that the agent was enjoying at the precise moment in which the energy service interfered with her? Or does it refer to a hypothetical situation that we have abstractly identified as a requirement of justice? Or both things?

Going straight to the point, consider a continuation of the example that we have adopted in this paper. The public authority that is in charge of choosing the place for the energy facility decides to install it in the suburb, hence depriving the inhabitants of the cultural centre. However, suppose that after ten years a new group of administrators of the public authority have to decide whether or not to continue the activities of the energy facility in the same location. They decide to keep things unaltered, but at the same time, they entrust two tiny public buildings, from that same suburb, to a cultural association that is supposed to take over, but on a much smaller scale, the activities that would have been organised in the old cultural centre. Is this second administration benefiting or harming the inhabitants of the suburb? Or in terms of capabilities, is this second administration promoting or limiting the inhabitants' capability for participating in shared cultural activities (from now on let's call it capability $\mathrm{P})$ ?

From a diachronic perspective, the second administration is benefiting residents because it is making them better off than they were before of its assignment - or, in a more analytical formulation, better off than they were before the new administration started interacting with them. Yet, residents still fall short from collectively exercising capability $\mathrm{P}$, because the resources allocated to the association only allow for very limited cultural initiatives. However, if we have reasons to believe that capability $\mathrm{P}$ is part of the minimum set of capabilities that we identify as central for living a life that has value, we should not judge the consequences of the actions performed by the second administration at 
time $t 2$ in comparison to the situation at time $t 1$, rather we ought to take as our benchmark a subjunctive condition in which our moral demands about capability $\mathrm{P}$ are met (Pogge 2008, 19-26). In our example, this benchmark can be indicated by the hypothetical situation in which every inhabitant of the suburb is provided with the means for having a reasonable chance of developing the capability for participating in shared cultural activities, regardless of whether this hypothetical situation has ever existed in history.

It might be objected that there is no reason to appeal to subjunctive and moralised baselines because we can reject the conclusion that a given action brings about a diachronic benefit by moving back in time the historical baseline. For example, in our case it can be argued that the second administration is not harming the local community in relation to the situation that was created by the first administration but is still causing harm with respect to the situation we had before the energy infrastructure took over the cultural centre. Unfortunately, this is not always true.

Imagine a modification of our example, in which the cultural centre had never existed in the area where the energy facility was settled. Within this scenario, there is no historical baseline we can refer to for denying that the second administration is benefiting the local community. Moreover, even in those cases in which we can find a historical baseline with regards to which a present outcome can be considered as worse off, there is no reason to believe that we should be morally satisfied with that baseline. This occurs in the original version of our example. If we adopt as a historical baseline the moment before the first administration decided to dismiss the cultural centre, we would have a benchmark that would allow us to maintain that the second administration is keeping on harming the local community instead of benefiting it, but this benchmark would not be satisfactory. For even though at that time people were closer to collectively exercising capability $\mathrm{P}$, they were still falling short of a full exercise of that capability, because in addition to the cultural centre they were lacking the social contribution needed to appreciate and to follow the activities of the centre.

On the other hand, the danger of adopting only subjunctive baselines for IDES consists in the fact that minor losses inflicted to individuals who start from high levels of capabilities might not be taken into account. Imagine that we hold that for capability $\mathrm{P}$ to be considered as collectively exercisable by a local community we need every member of this community to be given access to a minimum level of education and to spaces where to share cultural activities, and consider a case in which an energy infrastructure takes over a cinema in a central neighbourhood that has plenty of other cinemas. Since the loss of only one among many cinemas would not render anyone unable to meet the minimum requirements for exercising capability $P$, we would have to conclude that from our subjunctive prospective the loss of the cinema does not harm 
anyone in relation to capability $\mathrm{P}$. Whereas, diachronically it might still be possible to denounce the removal of the cinema as a loss for residents.

Shall it bother us? When talking of harm in general terms, the answer is yes. That is why we believe that Lukas Meyer $(2003,154-155)$ is perfectly right when he argues that both the historical and the subjunctive evaluations of harm are sufficient but not necessary conditions for ascertaining that an action has been harmful. Conversely, in the case of IDES, we are not sure that a reductionist account of harm stemming from the exclusive adoption of subjunctive thresholds does necessarily pose a problem, rather we believe that under the majority of circumstances it can be an advantage. For if every variation in the distribution of energy advantages were to be considered as harm, any egalitarian redistribution of costs would bring with itself a never-ending wake of compensations. On the contrary, from the subjunctive prospective, only the losses of resources that undermine the exercisability of those capabilities that we have chosen as central for the community will be weighted in the estimation of harm and will trigger compensatory duties. How do we decide which capabilities are central and which are not for a given community and whether the compensation for subjunctive harm based on capability thresholds could be non-monetary is the topic of the following section.

\section{Restoring Lost Capabilities Through Monetary and Non-monetary Compensation}

As we all know, Sen put much emphasis on the importance of capabilities for evaluating individual positions in society, but he never wanted to explicitly distinguish among those capabilities that are more central, or more basic, and the others - although we can attempt some normative inferences from his descriptive insights on the measurement of the quality of life. Whereas Nussbaum (2007, 76-77) made a famous list of the ten capabilities that she deems as central for any individual to live 'a life worthy of human dignity': 1) life, 2) bodily health, 3) bodily integrity, 4) senses, imagination, and thought, 5) emotions, 6) practical reason, 7) affiliation, 8) other species, 9) play, 10) control over one's environment. This list is supposed to represent a cosmopolitan minimum of social justice or, in other words, a necessary but not sufficient component of a comprehensive account of distributive justice.

Shall philosophers attempt to do the same within the more specific field of energy justice? That is to say, shall they propose a universal list of capabilities that cannot be undermined, in any case, by energy services? Probably there would not be enough space here to probe such an articulate normative issue. Moreover, notwithstanding the fact that a list of central capabilities would not run the risk of stumbling into paternalism, at least as long as capabilities are described in a general way and functionings are kept out of the normative discourse (Nussbaum 2007, 78-80), we are also convinced that with regards to 
energy justice it would make more sense to leave to single communities the onus of deciding which capabilities should be considered as central and which should not (Sen 2005; Robeyns 2006, 355-356; Biggieri et al. 2007).

Obviously, there are certain capabilities that relate to key functionings, as having good health, receiving enough nourishment, being protected from natural disasters, and so on, that we intuitively want to be given unbreakable priority by every social group. Thus, someone might demand these capabilities to be part of a universal list with respect to which we should evaluate energy harm. But on the other hand, the negative rights to life and health are already part of any credible account of justice, interpreted in a broad sense. Accordingly, when dealing with the specific issue of which capabilities should be considered as central in the definition of environmental harm, there is no alternative but to put in the list all the threats to bodily integrity.

Therefore, the political choice that we were arguing should be left to local policymakers pertains to the classification of the capabilities that usually relate to positive justice and that might be curtailed by energy services. The position of refraining from ranking or listing capabilities is also embraced by Sen $(2005,157)$, who affirms that such position is motivated by the difference of contexts in which communities live and by the importance of leaving room for public reasoning on the subject, instead of limiting it. At the same time, it can be noticed that Sen (1979) himself argued for interpreting needs as basic capabilities and he affirms that Rawls's concern with primary goods could be complemented with a focus on basic capabilities (Sen 1979, 21819), thereby implicitly admitting that some preeminent basic capabilities actually exist. Elaborating further on this idea of Sen (1979) that needs are interpretable as basic capabilities, it has been argued (Pellegrini-Masini 2019) that, since energy justice is rooted in the concept of equality (Pellegrini-Masini 2020a), energy justice promotes at least equal levels of basic capabilities and the satisfaction of basic needs. Holding this perspective would result in considering the protection of basic needs and their related basic capabilities as paramount for any energy policy and thereby implying the provision of compensation through restoration or indemnification. While drawing the line between basic needs and higher needs might be difficult, theories of needs have presented this distinction (Maslow 1987; Max-Neef 1992), which has also been confirmed by empirical research testing the hierarchy of needs of Maslow (Oishi et al. 1999; Sheldon et al. 2001; Taormina and Gao 2013).

Therefore, being basic needs and their corresponding basic capabilities worthy of protection above all other capabilities, it could be argued that what Max-Neef $(1992,206)$ indicates as 'subsistence' and 'protection', comprising respectively 'physical health, mental health, equilibrium, sense of humour, adaptability' and 'care, adaptability, autonomy, equilibrium, solidarity', and what Maslow (1987) similarly defines as physiological needs and safety needs, 
could be considered the basic needs corresponding to their related basic capabilities that require priority protection.

The very practical problem we face is what we shall do with activities that tarnish the human capabilities that have been judged as central in the assessment of IDES. Should they be stopped and the victims compensated? Or can these activities be continued and the victims compensated? In both cases, shall the compensation consist of the precise restoration of the resources that were guaranteeing the central capability that was lost? Is the perpetrator of energy harm free in deciding how to restore the capability? Can this compensation be monetary? Can it not be so?

First of all, the great advantage of using capabilities for measuring environmental harm is that this approach does not allow for monetary trade-offs across different spheres of interest - or across different central capabilities. ${ }^{6}$ In the sense that monetary compensation can be accepted only in those cases in which it can help the victim to restore the lost capability in the private market. But money cannot be accepted in all those other cases in which it is of no use for the victim for reaching the threshold that refers to the capability that has been tarnished by the compensator.

Consider again the example of an energy infrastructure that leaves the residents of an urban area with less green spots than it is allowed by the harm threshold related to the exercise of the central capability for enjoying nature in one's neighbourhood. Monetary compensation cannot be allowed in this situation, because it would be useless for the restoration of this capability. Conversely, monetary compensation can probably be accepted in the case of the loss of the capability for participating in shared cultural activities, provided that a private market for these activities exists and that the monetary compensation is enough for allowing the victims to access this market.

When a IDES would deprive some agents of a central capability that cannot be restored in a non-monetary way, and a monetary compensation would be ineffective with regards to the lost capability, the IDES is irreparable and thus impermissible. This is an important difference between IDES interpreted in terms of means to achievement and IDES based on capabilities. For if we only look at the economic value of lost assets, monetary compensation will always be an open option, at least theoretically, unless we impose the further clause that some forms of harm are impermissible per se. In the account of IDES that we are proposing, there are a series of horizontal thresholds that do not allow for any trade-off. That is, we believe that for some central or basic capabilities (as those earlier indicated) there cannot be neither monetary trade-offs, unless they are suitable to restore the lost capability, nor trade-offs between capabilities (see also Axelsen and Nielsen 2015).

The capability approach that we are proposing in this paper, contrasts instead with mainstream energy policies underpinned by neoliberalist thinking, which compresses the role of citizens to that of consumers with seemingly mostly 
economic rights (Willow 2016; Lennon et al. 2020). In current times, compensation for energy infrastructure siting is seldom discussed and developers are reluctant to talk about it (Cass, Walker, and Devine-Wright 2010), although this has been researched, in terms of economic compensation, with regards to wind farms (P. A. Groothuis, J. D. Groothuis, and Whitehead 2008). In particular, the wind farms example is illuminating about how the energy industry has tried to avoid compensation discourses and to limit any measure in favour to local communities to community benefits, being these financial or 'in kind' (Pellegrini-Masini 2020). Most often wind energy community benefits, in all their forms, are not negotiated with the community but follow industry customary practices (e.g., in the UK) or country laws (e.g., in Spain and Germany). This might strengthen the position of socially deprived communities, which might have less ability of negotiating, but it might also prevent those communities, which might be capable of advancing their arguments, from asking for the protection or restoration of their threatened capabilities.

\section{Conclusions}

In this article, we faced two of the four questions that political and moral theorists should respond to when dealing with the distributive component of the notion of energy justice. First, we argued that only by adopting capabilities as the currency of justice we can obtain a comprehensive assessment of IDES, which is immune to adaptive preferences and gives due weight to those individual and social heterogeneities that may cause two different agents to suffer two different losses of wellbeing due to an energy service that deprives them of the same set of resources. Second, we argued that marginal increases and losses of capabilities caused by energy services should not be calculated in relation to a diachronic benchmark, rather to a hypothetical and moralised threshold (or series of horizontal thresholds) that correspond to something similar (if not equivalent) to the account of Nussbaum's list of ten central capabilities and which relates to well established theories of needs.

In the last section of the article, we addressed the issue of compensation of an agent who has been deprived of a central capability by an energy service. We maintained that when the central capability cannot be restored in a non-monetary way and monetary compensation is ineffective, the performance of the energy service is impermissible. Accordingly, from a normative point of view, either the policymaker relocates the infrastructure(s) that supplies the energy service to a place where nobody would suffer non-compensable losses of central capabilities or she renounces the supply of this service. A moral conflict can arise only on condition that the energy infrastructure cannot be relocated to a place where central capabilities are not jeopardised and the decision to renounce the supply of the energy service may have as a consequence the loss of some other central capabilities by the prospective recipients of the energy service. Given the very restrictive scope of a list of basic or central 
capabilities that can be drawn, we assume that the trade-off between central capabilities can be caused by energy services only on rare and extreme occasions. In these situations, the choice should be democratic and it forms part of the political responsibility of policy-makers.

In the end, by combining the informational focus of capabilities (currency) with a hypothetical and moralised interpretation of marginalities, we come up with an evaluative account of IDES that is based on two parameters: the centrality of the individual capabilities involved and the number of people affected. These parameters should be read in a lexicographic order, in the sense that safeguarding central capabilities should take precedence over any aggregative calculus. Meaning that a large group of people losing non-central capabilities should never outweigh even only one person losing a central capability. Aggregative reasoning is allowed only in those cases in which two different individuals (or group of individuals) are at risk of losing central capabilities. ${ }^{7}$

In developing this theoretical standpoint on compensation for IDES based on the capabilities approach, we have proposed an innovative approach to compensation policies that we wish might be discussed in policymaking.

The vision proposed does not counter traditional principles adopted to address the problem of compensation for threatened community environments: the 'property rule' and the 'liability rule' (Cowell, Bristow, and Munday 2011). The first rule presupposes a negotiation with the community which must consent ex-ante an intervention on the environment that a community owns; while the second gives prominence to the rights of a third party to make an intervention in a certain environment, but it grants the community to have a compensation ex-post. Most likely the adoption of a compensation framework based on the capability approach could be used within the 'liability rule', but it could also be embedded in the planning process itself, in order to pre-asses the costs that the community might suffer from a proposed energy infrastructure in terms of loss of capabilities.

The capability approach to compensation is also flexible to a good extent because, as earlier argued, and as contended by Sen $(1979,2005)$, there might be a core of fundamental capabilities, but other capabilities are context-dependent and are shaped by local cultures. Therefore it is possible to integrate a capability approach to compensation in cultural and political contexts as diverse as those that worldwide host energy infrastructures, whose acceptability is often challenged on local cultural terms (see i.e., Zárate-Toledo, Patiño, and Fraga 2019; Velasco-Herrejon and Bauwens 2020).

\section{Notes}

1. The other two issues about which philosophers could contribute to the ongoing debate, and which we do not address in this article, concern the scope and the pattern of energy distributive justice. 
2. We are grateful to an anonymous reviewer for helping us to clarify this point.

3. See also the definition of energy poverty in terms of capabilities given by Day, Walker, and Simcock $(2016,260)$.

4. For a detailed analysis of the relation between egalitarianism and capabilities (see Sen 1992).

5. For an overview of non-comparative accounts of harm (see Boonin 2014, 71-102).

6. At least in the original formulation given by Nussbaum.

7. In these situations, it might be also possible to integrate the aggregative reasoning with further vertical distinctions between central capabilities, or, in other words, with considerations regarding which central capabilities are 'more central' than other central capabilities.

\section{Disclosure statement}

No potential conflict of interest was reported by the author(s).

\section{Funding}

Giuseppe Pellegrini-Masini, was sponsored by the European Union's Horizon 2020 research and innovation programme under grant agreement No 763912 of the SMARTEES project. Stefano Maran acknowledges the financial support of the Research Fund for the Italian Electrical System, in compliance with the Decree of Minister of Economical Development (Ministero dello Sviluppo Economico) April 16, 2018.

\section{Notes on contributors}

Fausto Corvino is Postdoctoral Research Fellow in Theoretical Philosophy in the Department of Philosophy and Educational Sciences at the University of Turin. He is also member of Labont (Center for Ontology) at the University of Turin, affiliate researcher (since 2020) in the DIRPOLIS Institute (Law, Politics and Development) and member of the Research Group on Public Ethics (since 2018) at Sant'Anna School of Advanced Studies, in Pisa. Prior to this, Fausto was Postdoctoral Research Fellow in Moral Philosophy at Sant'Anna School of Advanced Studies (2018-2020), where he also holds a PhD (2017) in Politics, Human Rights and Sustainability (with a research curriculum in political theory). His main research interests lie in theories of distributive justice (including global and intergenerational justice), philosophy of economics and applied ethics (including the ethics of climate change).

Giuseppe Pellegrini-Masini is a Postdoctoral Research Fellow at the Norwegian University of Science and Technology (Trondheim). He is an environmental social scientist working on the H2020 SMARTEES research project, which studies through a multimethod approach, the drivers and barriers affecting the development of energy social innovations involving renewables, sustainable transportation and energy efficiency in buildings. His specific focus is on energy equality, energy justice and energy efficiency in urban areas. Previously he was a postdoctoral fellow, and now he is an Affiliate Researcher at the Sant'Anna School of Advanced Studies (Pisa, Italy), where he worked on a research project in collaboration with RSE, (Ricerca sul Sistema Energetico, Milano), on energy justice and the social aspects related with the evolution of the Italian energy system. In 2017, he was awarded a $\mathrm{PhD}$ at Heriot-Watt University, (School of Energy, Geoscience, Infrastructure and 
Society), where he researched social acceptability of onshore wind farms and the co-operative model of community ownership.

Alberto Pirni is Associate Professor in Moral Philosophy at the 'Law, Politics and Development Institute' of the Sant'Anna School for Advanced Studies, where he teaches 'Public Ethics', 'Ethics of Care Relationship', 'Ethics of Security', and 'Theories of Intergenerational Justice'. $\mathrm{He}$ is Vice-President of the Joint Ethical Committee between Sant'Anna School of Advanced Studies and Scuola Normale Superiore and member of the Steering Committee of the Master Programm in 'International Security Studies'. He teaches also Public Ethics as Adjunct Professor at the 'Università Cattolica del Sacro Cuore' (Milan). He spent research periods by the Universities of Tübingen and Freiburg i.Br. (Germany). Visiting Professorships include the Universidad Autónoma de Madrid, the Universität Vechta (Germany), the Saint Petersburg State University (Russian Federation), the Universidade Federal de Santa Catarina, Florianópolis (Brazil), Universidad Nacional de Rosario and Universidad de Buenos Aires (Argentine). Main research fields involve: Kant and Classical German philosophy; contemporary political and social philosophy; public ethics; ethics of technology; ethics and economics; theories of justice. Since its foundation (1998) he is the coordinator of the Acqui Terme Summer School in Philosophy (Alessandria, Italy) in partnership with the Italian Institute for Philosophical Studies.

Stefano Maran currently works at the Sustainable Development and Energy Sources Department, Ricerca Sistema Energetico. Stefano does research in Decision Support Systems, Geographical Information Systems, Environmental and Social impacts of the energy system. He was the coordinator of the INSPIRE-Grid project (http://inspire-grid. $\mathrm{eu}$ ), about the engagement of stakeholders in the development of the electricity grid.

\section{References}

Alkire, S. 2005. "Needs and Capabilities." Royal Institute of Philosophy Supplement 57: 229-252.

Alkire, S. 2008 . Using the Capability Approach: Prospective and Evaluative Analyses. In The Capability Approach: Concepts, Measures and Applications, edited by F. Comim, M. Qizilbash, and S. Alkire, 26-49. Cambridge: Cambridge University Press.

Alkire, S., J. E. Foster, S. Seth, M. E. Santos, J. M. Roche, and P. Ballon. 2015. Multidimensional Poverty Measurement and Analysis. Oxford: Oxford University Press. Arneson, R. J. 2000. "Welfare Should Be the Currency of Justice." Canadian Journal of Philosophy 30 (4): 497-524.

Axelsen, D. V., and L. Nielsen. 2015. "Sufficiency as Freedom from Duress." The Journal of Political Philosophy 23 (4): 406-426. doi:10.1111/jopp.12048.

Barnes, E. 2009. "Disability and Adaptive Preference." Philosophical Perspectives 23 (1): 1-22. doi:10.1111/j.1520-8583.2009.00159.x.

Biggieri, M., R. Libanora, S. Mariani, and L. Menchini. 2007. "Children Conceptualizing Their Capabilities: Results of a Survey Conducted During the First Children's World Congress on Child Labour." Journal of Human Development 7 (1): 59-83. doi:10.1080/ 14649880500501179.

Boonin, D. 2014. The Non-Identity Problem and the Ethics of Future People. Oxford: Oxford University Press.

Bovens, L. 1992. “Sour Grapes and Character Planning." Journal of Philosophy 89 (2): 57-78. doi:10.2307/2027152. 
Bromley, D. W., and J. Paavola. 2002. "Economics, Ethics and Environmental Policy.” In Economics, Ethics, and Environmental Policy: Contested Choices, edited by D. W. Bromley and J. Paavola, 261-276. Oxford: Blackwell.

Bruckner, D. W. 2009. "In Defense of Adaptive Preferences." Philosophical Studies 142 (3): 307-324. doi:10.1007/sl1098-007-9188-7.

Cass, N., G. Walker, and P. Devine-Wright. 2010. “Good Neighbours, Public Relations and Bribes: The Politics and Perceptions of Community Benefit Provision in Renewable Energy Development in the UK." Journal of Environmental Policy and Planning 12 (3): 255-275. doi:10.1080/1523908X.2010.509558.

Comim, F. 2008. "Measuring Capabilities." In The Capability Approach: Concepts, Measures and Applications, edited by F. Comim, M. Qizilbash, and S. Alkire, 157-200. Cambridge: Cambridge University Press.

Corvino, F. 2019. “Utility, Priorities, and Quiescent Sufficiency.” Etica \& Politica / Ethics \& Politics 21 (3): 525-552. doi:10.13137/1825-5167/29519.

Cowell, R., G. Bristow, and M. Munday. 2011. "Acceptance, Acceptability and Environmental Justice:The Role of Community Benefits in Wind Energy Development." Journal of Environmental Planning and Management 54: 539-557. doi:10.1358/2011.47.3.1556471.

Day, R., G. Walker, and N. Simcock. 2016. "Conceptualising Energy use and Energy Poverty Using a Capabilities Framework.” Energy Policy 93: 255-264. doi:10.1016/j.enpol.2016.03. 019.

Elster, J. 1983. Sour Grapes: Studies in the Subversion of Rationality. Cambridge: Cambridge University Press.

Enetjärn, A., S. Cole, M. Kniivilä, S. E. Hårklau, L. Hasselström, T. Sigurdson, and J. Lindberg. 2015. Environmental Compensation: Key Conditions for Increased and Cost Effective Application. Copenhagen: Nordic Council of Ministers.

Eyre, N. 1997. "External Costs: What Do They Mean for Energy Policy?" Energy Policy 25 (1): 85-95. doi:10.1016/S0301-4215(96)00124-3.

Groothuis, P. A., J. D. Groothuis, and J. C. Whitehead. 2008. "Green vs. Green: Measuring the Compensation Required to Site Electrical Generation Windmills in a Viewshed." Energy Policy 36 (4): 1545-1550. doi:10.1016/j.enpol.2008.01.01.

Hillerbrand, R. 2018. "Why Affordable Clean Energy Is Not Enough. A Capability Perspective on the Sustainable Development Goals." Sustainability 10: 1.14. doi:10. 3390/su10072485.

Jenkins, K., D. McCauley, R. Heffron, H. Stephan, and R. Rehner. 2016. “Energy Justice: A Conceptual Review.” Energy Research and Social Science 11: 174-182. doi:10.1016/j.erss. 2015.10.004.

Lennon, B., N. Dunphy, C. Gaffney, A. Revez, G. Mullally, and P. O’Connor. 2020. "Citizen or Consumer? Reconsidering Energy Citizenship." Journal of Environmental Policy and Planning. Routledge 22 (2): 184-197. doi:10.1080/1523908X.2019.1680277.

Maslow, A. H. 1987. Motivation and Personality. 3rd ed. New York; London: Harper \& Row.

Max-Neef, M. 1992. "Development and Human Needs." In Real-Life Economics: Understanding Wealth Creation, edited by Paul Ekins, and Manfred Max-Neef, 197-214. Routledge. doi:10.4324/9781315258003-14.

McCauley, D. 2018. Energy Justice: Re-Balancing the Trilemma of Security, Poverty and Climate Change. London: Palgrave Macmillan.

Meyer, L. M. 2003. "Past and Future: The Case for a Threshold Notion of Harm." In Rights, Culture and the Law: Themes from the Legal and Political Philosophy of Joseph Raz, edited by L. M. Meyer, S. Paulson, T. Pogge, and Thomas, 143-158. Oxford: Oxford University Press.

Mulgan, T. 2007. Understanding Utilitarianism. Stocksfield: Acumen. 
Nussbaum, M. 2000. Women and Human Development: The Capability Approach. Cambridge: Cambridge University Press.

Nussbaum, M. 2001. "Symposium on Amartya Sen's Philosophy: 5 Adaptive Preferences and Women's Options." Economics and Philosophy 17 (1): 67-88. doi:10.1017/ S0266267101000153.

Nussbaum, M. 2007. Frontiers of Justice: Disability, Nationality, Species Membership. Cambridge, MA: Harvard University Press.

Oishi, S., E. F. Diener, R. E. Lucas, and E. M. Suh. 1999. "Cross-Cultural Variations in Predictors of Life Satisfaction: Perspectives from Needs and Values." Personality and Social Psychology Bulletin 25 (8): 980-990. doi:10.1177/01461672992511006.

Pellegrini-Masini, G. 2019. "Energy Equality and Energy Sufficiency: New Policy Principles to Accelerate the Energy Transition." In ECEEE 2019 Summer Study Proceedings, 143148.

Pellegrini-Masini, G., A. Pirni, and S. Maran. 2020a. "Energy Justice Revisited: A Critical Review on the Philosophical and Political Origins of Equality." Energy Research and Social Science 59: 1-7. doi:10.1016/j.erss.2019.101310.

Pellegrini-Masini, G., A. Pirni, S. Maran, and C. A. Klöckner. 2020b. "Delivering a Timely and Just Energy Transition: Which Policy Research Priorities?" Environmental Policy and Governance 30: 293-305. doi:10.1002/eet.1892.

Pellegrini-Masini, G. 2020. Wind Power and Public Engagement, Co-Operatives and Community Ownership. London: Routledge. doi:https://doi.org/10.4324/9780429491894.

Pogge, T. 2008. World Poverty and Human Rights. Cambridge: Polity Press.

RGI. 2018. Community Payments - Case Studies from Across Europe. 2nd ed. Renewables Grid Initative. Accessed September 9 2020. https://renewables-grid.eu/topics/ community-payments.html.

Robeyns, I. 2006. “The Capability Approach in Practice." The Journal of Political Philosophy 14 (3): 351-376. doi:10.1111/j.1467-9760.2006.00263.x.

Robeyns, I. 2017. Wellbeing, Freedom and Social Justice: The Capability Approach ReExamined. Cambridge: Open Book Publishers.

Sen, Amartya. 1979. Equality of What? The Tanner Lecture on Human Values. Stanford: Stanford University.

Sen, A. 1992. Inequality Reexamined. Cambridge, MA: Harvard University Press.

Sen, A. 1999. Development as Freedom. Oxford: Oxford University Press.

Sen, A. 2005. "Human Rights and Capabilities." Journal of Human Development 6 (2): 151166. doi:10.1080/14649880500120491.

Sheldon, K. M., A. J. Elliot, Y. Kim, and T. Kasser. 2001. "What is Satisfying About Satisfying Events? Testing 10 Candidate Psychological Needs." Journal of Personality and Social Psychology 80 (2): 325-339. doi:10.1037/0022-3514.80.2.325.

Sorensen, J. H., J. Soderstrom, and S. A. Carnes 1984. "Sweet for the Sour: Incentives in Environmental Mediation.” Environmental Management 8 (4): 287-294. doi:10.1007/ BF01868028.

Taormina, R. J., and J. H. Gao. 2013. "Maslow and the Motivation Hierarchy: Measuring Satisfaction of the Needs." The American Journal of Psychology 126 (2): 155-177. doi:10.5406/amerjpsyc.126.2.0155.

UNESCO. 1971. Convention on Wetlands of International Importance Especially as Waterfowl Habitat - Ramsar, Iran. https://www.ramsar.org/sites/default/files/ documents/library/current_convention_text_e.pdf.

Vallentyne, P., and B. Tungodden. 2013. "Liberal Resourcism: Problems and Possibilities." Journal of Social Philosophy 44 (4): 348-336. doi:10.1111/josp.12045. 
Velasco-Herrejon, P., and T. Bauwens. 2020. "Energy Justice from the Bottom Up: A Capability Approach to Community Acceptance of Wind Energy in Mexico." Energy Research and Social Science 70 (101711): 1-15. doi:10.1016/j.erss.2020.101711.

Welsch, Heinz. 2016. "Electricity Externalities, Siting, and the Energy Mix: A Survey". International Review of Environmental and Resource Economics. Now Publishers Inc. doi:10.1561/101.00000083.

Willow, A. J. 2016. "Wells and Well-Being: Neoliberalism and Holistic Sustainability in the Shale Energy Debate.” Local Environment. Routledge 21 (6): 768-788. doi:10.1080/ 13549839.2015.1017808.

Wood, N., and K. Roelich. 2019. "Tensions, Capabilities, and Justice in Climate Change Mitigation of Fossil Fuels.” Energy Research \& Social Science 52: 114-122. doi:10.1016/ j.erss.2019.02.014.

Zárate-Toledo, E., R. Patiño, and J. Fraga. 2019. “Justice, Social Exclusion and Indigenous Opposition: A Case Study of Wind Energy Development on the Isthmus of Tehuantepec, Mexico.” Energy Research and Social Science 54: 1-11. doi:10.1016/j.erss. 2019.03.004. 